\title{
Globalization, Agro-Based Industry and Unemployment: A Three-Sector General Equilibrium Model
}

\author{
Sushobhan Mahata ${ }^{*}$ and Ranjanendra Narayan $\mathrm{Nag}^{2}$ \\ ${ }^{1}$ University of Calcutta, Kolkata, West Bengal, India \\ ${ }^{2}$ St. Xavier's College (Autonomous), Kolkata, West Bengal, India \\ "Corresponding author: sushobhanmahata@gmail.com
}

\begin{abstract}
This paper explains how different interconnected measures of globalization, namely, tariff reform, labour market reform and capital account liberalization influence different sectors of the economy, unemployment and flexible wage of unskilled labour in the informal sector. In so doing we depart from the conventional Harris-Todaro type of model of open urban unemployment. The different comparative static exercises performed in a three-sector general equilibrium clearly indicate that globalization is not a panacea for the multitude of problems of an emerging market economy.

JEL Classification- E26, F16
\end{abstract}

Keywords: Agro-based industry, unemployment, informal sector

Globalization has impacted the world economy in several aspects, including inter alia movement of goods and labour across borders, free flow of knowledge, access to the capital market of foreign countries. The channel through which these seemingly exciting process works requires careful attention. The $20^{\text {th }}$ century had witnessed a list of countries (including India, Pakistan, Myanmar and China) that were liberalized along their macroeconomic and trading fronts. This process being promoted by the idea of globalization; the liberalization of the overseas trade regime was also expected to improve a docile atmosphere among nations. Such breakthrough reforms are usually complemented by certain other domestic reforms such as labour market reform, domestic capital market reform etc. India, with no exception, had introduced reforms partially during the 1980s and the period marked economic recovery, however, GDP did not grow much and finally, the growing structural imbalances and the Gulf crisis forced India to resort to the IMF and World Bank for borrowings to stabilize the economy. The conditionality imposed by the IMF- World Bank to bail out India from its economic crisis, were later introduced as Economic Reforms during 1991. Given this backdrop, the present paper attempts to analyze the engagement of reform policies with the informal sector in terms of the wage gap between formal and informal sector, informalization of workforce and growth of the informal sector. There are enormous literature that modelled informal sector under different perspectives. We consider few of them relevant to our paper. Marjit, Kar and Sarkar (2004) analyzed the effect of capital mobility across sectors in determining wage inequality. The paper obtained that under full employment condition and immobility of capital across the formal and informal sector, wage inequality can be reduced by tariff liberalization, while the exact opposite holds under perfect capital mobility. Marjit and Beladi (2005) investigate the effect of trade in increasing employment of informal labour using a Harris Todaro model. Chaudhuri and Banerjee (2006) obtained that labour market reform and capital account liberalization can have a positive effect on informal sector wage provided capital is perfectly mobile between intermediate input industry and the 
agriculture sector. In most of the literature either full employment had been assumed or Harris-Todaro type open unemployment of unskilled labour had been considered. Our departure from Marjit and Beladi (2005) and Chaudhuri and Banerjee (2006) are in terms of elimination of urban unemployment of skilled labour which has been discussed in further sections. We also depart from the conventional Harris-Todaro type of open urban unemployment.

The rest of the paper is organized as follows. In section 2 we critically discuss the H-T type of open unemployment and provide an alternative perspective. In section 3 we build our basic model and consider two sub-cases with respect to sectoral capital mobility. Finally, section 4 concludes the paper.

\section{Harris-Todaro Unemployment Model - A Brief Critique}

A typical H-T model states that at equilibrium between expected urban wage and actual rural wage, urban unemployment exists and any urban development program without sufficient growth in rural sector would aggravate urban unemployment. Policy analysis related to urban unemployment can be found in general equilibrium literature as well which incorporates $\mathrm{H}-\mathrm{T}$ equilibrium condition. Such general equilibrium structure proves the conventional H-T results. A subset of such literature includes Marjit (1991), Corden and Findlay (1975) and Beladi and Marjit (1996). However, those analyses are subject to certain criticism. First, unskilled labour could not afford to remain unemployed in the urban sector since they come from a relatively poorer background and affording urban life without any present employment but with a future expectation of earning cannot be an adequate logic. ${ }^{1}$ Second, large growing share of the informal sector in providing employment (which is roughly around $89 \%$ in India) is evidence that failure of employment generation in the formal sector leads to absorption of excess labour in the informal sector. Under this section, we shall try to provide an intuitive formulation to explain under what condition unemployed workers in the

\footnotetext{
${ }^{1}$ Any unskilled labour migrated to any metropolitan (urban) city in search of an urban job will die if he/she waits for formal sector employment in expectation of future income without any current income to feed himself/herself in the current period.
}

urban sector would choose to get employed in the low paying urban informal sector. The below diagram can be used to explain the non-existence of unemployment of urban unskilled labour in an intuitive sense.

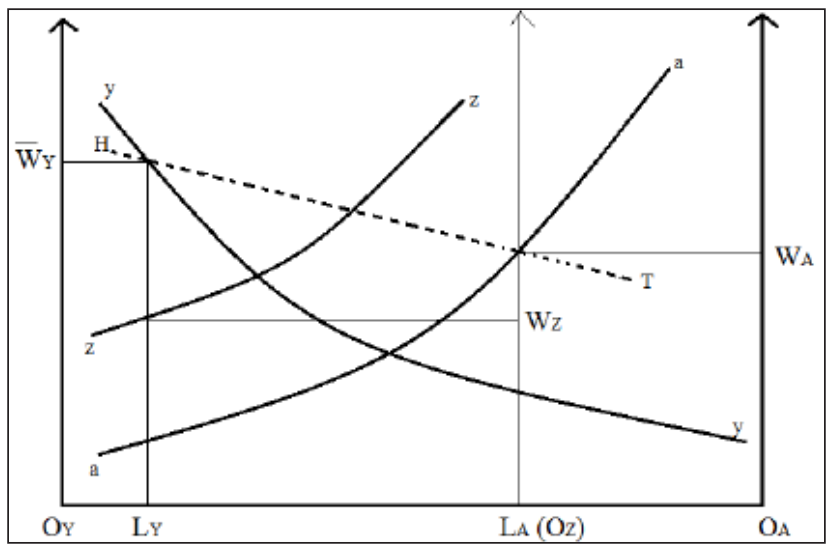

Define sector $Y$ (urban formal sector), sector A (rural sector) and sector $\mathrm{Z}$ (urban informal sector). The marginal productivities curve are $y y$, aa and zz respectively for $Y, A$ and $Z$. Finally, the HT curve gives the migration equilibrium condition. At initial stage expected urban wage is higher and set institutionally at $W_{\gamma}$ than rural competitive wage, $W_{A^{\prime}}$ thus urban unemployment exists by the amount $L_{Y} L_{A}\left(O_{Y} L_{A}-O_{Y} L_{Y}\right)$. Literature adopting H-T model ignored the opportunity cost of remaining unemployed. The opportunity cost of remaining unemployed is the forgone current informal wage rate and the benefit of remaining unemployed is the future higher formal wage rate. Unemployed workers frame their optimal decision and choose to engage in the informal sector under the sufficient condition,

$$
W_{Z}>p \bar{W}_{Y}, \quad \mathrm{p}<1
$$

Where ' $p$ ' is the probability of getting employed in the formal sector $Y$. The condition is stronger in the sense that $W_{Y}>W_{Z}$, since formal sector pays higher return than informal sector. The sufficient condition stated above depicts that workers would be fully employed in the informal sector if current informal sector wage is higher than the expected formal wage rate. Therefore, workers $L_{Y} L_{A}$ now get employed in the informal sector.

\section{The Basic Model with Full Employment}

We consider a small open developing economy with three sectors of production. Sector $X$ produces a 
high skilled commodity using skilled labour and capital, Sector $Y$ is a formal manufacturing sector using unskilled labour and capital, and finally sector $\mathrm{Z}$ is informal agro-based sector ${ }^{2}$ using unskilled labour and capital. We assume that sector $X$ and sector $\mathrm{Z}$ are the export sector and sector $\mathrm{Y}$ is the net importer protected by the tariff. Technology is CRS and there is diminishing marginal productivities to factors of production. Output market is assumed to be perfectly competitive and product prices are given in the international market ${ }^{3}$. We further assume that foreign capital and domestic capital are perfect substitutes. Return to specific factor skilled labour is competitively determined in the skilled labour market. Returns to other factors are discussed in further sub-cases. We bring into two dimensions of about capital specificity (mobility) across sectors. In first sub case we assume that capital of type 1 is mobile between formal sectors only (between $\mathrm{X}$ and $\mathrm{Y}$ ), while type 2 capital is specific to the informal sector. The second sub case eliminates this differentiation of capital specificity and assumes perfect capital mobility across the formal and informal sector. This completes general description of the assumed economic structure.

\section{The Structure of the Formal and the Informal Sector}

Developing nations are usually characterized by large informal sectors ${ }^{4}$ which acts as an important pillar for the economy that absorbs the burden of semi-skilled and unskilled labour with a lower level of education and lower productivities, by providing them income and employment, and hence the

\footnotetext{
${ }^{2}$ The agricultural sector is here referred to as any agro-based industry that produces its output using agricultural raw materials as one of the inputs, however we depart from this and consider only unskilled labour and capital as factors of production. Such kind of agro-based industries has huge export potential in any developing nation and thus it is considered as an export sector. In general, Sector $Z$ can also be considered as the broad informal manufacturing sector.

${ }^{3}$ Given the assumption of a small open economy, this implies that aggregate trade volume of our hypothetical economy constitutes meagre fraction relative to world trade volume. Therefore, the assumed economy cannot alter the world prices by its demand for imports and supply of exports.

${ }^{4}$ Informal sector or unorganized sector is referred to as those unregistered manufacturing units employing 10 or less workers with power or, 20 or less workers without power. These sectors are usually deprived of any perks or employment benefits and are out of Govt. regulations.
}

formal sector escapes from this darker side of the economy and operates in a formal space reaping all economic benefits. However, the quality of income and employment provided by the undernourished informal sector is far from satisfactory. In India, at the national level, the informal manufacturing sector is comprised mainly of agro-based consumer goods industry and resource-based intermediate industries (Saikia, 2017). In the present theoretical model, we differentiate formal and informal sector in terms of wage differential across the sectors. We assume that unskilled labour in the formal sector earns higher wage rate than their counterparts in the informal sector earning lower competitive wage rate $^{5}$. This captures the labour market distortion in the economy, however despite higher wage rate in the formal sector there exists no unemployment of the unskilled labour'.

\section{Sub case 1: Sector - Specific Capital}

We assume that formal sector (i.e. sector $X$ and $Y$ ) uses capital of type 1 , while the informal sector uses capital of type 2 . Both types of capital earns different returns. Hence capital is completely immobile between formal and the informal sector.

Following symbols are used in the description of the model.

$a_{j i}$ : amount of $\mathrm{j}^{\text {th }}$ input required in per unit production in $\mathrm{i}^{\text {th }}$ sector, $j=S, L, K_{1}, K_{2} ; i=X, Y, Z$

$S$ : supply of skilled labour.

L : supply of unskilled labour.

$\mathrm{K}_{1}$ : supply of type1 capital.

$\mathrm{K}_{2}$ : supply of type 2 capital.

$\mathrm{W}_{\mathrm{S}}$ : return to skilled labour.

$\overline{\mathrm{W}}$ : return (unionized wage) to unskilled labour in the formal sector.

\footnotetext{
${ }^{5}$ Workers in the formal sector earns a higher wage rate due to factor such as presence of strong workers union that bargains over return to workers, also, formal sector wage rate are indexed to food price which acts as a protection against food inflation, moreover minimum wage legislation is generally effective in the formal sector.

${ }^{6}$ An unskilled worker who fails to get a job in the formal sector at prevailing higher wage rate, moves to the informal sector and gets employed in the informal sector due to informal wage flexibility. This is due to the simple fact that unskilled workers cannot afford to remain unemployed as the Harris- Todaro (1970) model suggests, in fact, they actively search for an alternative way to earn a livelihood for sustenance. Given this perspective, our assumption of the non existence of urban open unemployment is not far from reality.
} 
$\mathrm{W}$ : return to unskilled labour in the informal sector.

$\mathrm{r}_{1}$ : return to capital of type 1.

$\mathrm{r}_{2}$ : return to capital of type 2 .

$\mathrm{t}:$ import tariff rate.

$\mathrm{U}$ : union strenght in the formal sector.

$X$ : output of export sector.

Y : output of import competing (formal) sector.

$Z$ : output of agricultural export (informal) sector. $\mathrm{P}_{\mathrm{i}}^{*}$ : world price of $\mathrm{i}^{\text {th }}$ commodity, where $i=X, Y, Z$

The general equilibrium structure of the economy is represented by following equations:

$$
\begin{gathered}
W_{S} a_{S X}+r_{1} a_{(k 1) X}=P_{X}^{*} \\
\bar{W} a_{L Y}+r_{1} a_{(k 1) Y}=P_{Y}^{*}(1+t)=P_{Y} \\
W a_{L Z}+r_{2} a_{(k 2) Z}=P_{Z}^{*} \\
\bar{W}=\bar{W}(W, U) ; \frac{\partial \bar{W}}{\partial W}>0, \frac{\partial \bar{W}}{\partial U}>0 \\
a_{S X} X=S \\
a_{L Y} Y+a_{L Z} Z=L \\
a_{(k 1) X} X+a_{(k 1) Y} Y=K_{1} \\
a_{(k 2) Z} Z=K_{2}
\end{gathered}
$$

Equation (2.1)-(2.3) gives the three zero profit condition. Equation (2.4) gives the formal wage function which depends positively on informal competitive wage rate and bargaining strength of union. This is simple to understand. Labour union in the formal sector bargains over benchmark wage which is competitive wage rate in the informal sector, however in absence of bargaining strength formal wage would converge to informal wage rate. Equation (2.5)-(2.8) gives the full employment condition.

From eq. (2.5) we get,

$$
X=\frac{S}{a_{S X}}
$$

${ }^{7}$ The higher union wage rate can also be interpreted in terms of efficiency wage which varies with the rate of unemployment in that sector. For more detailed discussion see Shapiro and Stiglitz (1984), "Equilibrium Unemployment as a Workers Discipline Device", in American Economic Review.
Substituting (2.5.1) in eq. (2.7) we obtain,

$$
Y=\frac{K_{1}}{a_{(k 1) Y}}-\left(\frac{a_{(k 1) X}}{a_{S X} a_{(k 1) Y}}\right) S
$$

From eq.(2.8) we get,

$$
Z=\frac{K_{2}}{a_{(k 2) Z}}
$$

Substituting eq. (2.5.1), (2.7.1) and (2.8.1) in eq. (2.6), we get,

$$
\left(\frac{a_{L Y}}{a_{(k 1) Y}}\right) K_{1}-\left(\frac{a_{L Y} a_{(k 1) X}}{a_{S X} a_{(k 1) Y}}\right) S+\left(\frac{a_{L Z}}{a_{(k 2) Z}}\right) K_{2}=L
$$

$W_{S^{\prime}} r_{1^{\prime}}, \bar{W}, W, r_{2^{\prime}} X, Y, Z$ are the eight endogenous variables in the model and the policy parameters are $t, U, K_{1}, K_{2}$. The factor prices $W_{S^{\prime}} r_{1^{\prime}}, W, W, r_{2}$ are determined from the price system equations i.e. from eq. (2.1) - (2.4) and endowment eq. (2.6.1). Therefore, the model does not possess decomposition property ${ }^{8}$. Once factor prices are obtained, factor coefficients can also be obtained as these are functions of factor prices. Finally, equations (2.5.1), (2.7.1) and (2.8.1) solves for $X, Y$ and $Z$ respectively. This completes the determination of the model.

\section{Comparative Statics-I}

In this section, we carry out certain comparative statics pertaining to our analysis of globalization and related reforms that usually complements the process of globalization. In particular, we consider the effect of trade liberalization in terms of decline in tariff rate, deregulation of FDI in terms of increase in foreign capital inflow and labour market reform in terms of decline in union bargaining power ${ }^{9}$.

\section{Tariff Liberalization}

Improvement in trade liberalization or product market reform implies a fall in tariff rate. Due to fall in tariff rate, the domestic price of the import competing sector falls. This leads to contraction of the import competing sector and releases unskilled labour and type 1 capital. Since type 1 capital is mobile between the formal sectors only, therefore it moves to the export sector $X$, lowering the return on type 1 capital. Sector $X$ expands and its demand

\footnotetext{
${ }^{8}$ Since, the model does not possess decomposition property this implies any change in factor endowment would affect factor prices. ${ }^{9}$ See Appendix for the detailed mathematical derivation of all comparative statics result.
} 
for skilled labour rises, as a result, skilled wage rate goes up. The released unskilled labour moves to sector $\mathrm{Z}$ and thus lowering the competitive wage rate of informal labour and also lowers the formal wage rate. Since sector $Z$ expands, its demand for type 2 capital which is specific to the informal sector goes up, thus escalating the return on type 2 capital.

By taking total differentiation of eq. (2.1)-(2.4) and eq. (2.6.1), we get the following results,

$$
\begin{gathered}
\frac{\widehat{W}_{S}}{\hat{t}}=-\left\{\theta_{(k 1) X} \theta_{L Z} C-\theta_{(k 1) X} \theta_{(k 2) Z}\left(D S_{W}+E\right)\right\} T /|\Delta| \\
<0 ; D<0 \text { and } E<0
\end{gathered}
$$$$
\frac{\widehat{W}}{\hat{t}}={ }_{S X} \theta_{(k 2) Z} A T /|\Delta|>0 ; A>0
$$$$
\frac{\hat{r}_{1}}{\hat{t}}=\theta_{S X}\left(-D S_{W} \theta_{(k 2) Z}+\theta_{L Z} C-\theta_{(k 2) Z} E\right) T /|\Delta|
$$$$
>0 ; D<0, E<0 C>0
$$$$
\frac{\hat{r}_{2}}{\hat{t}}=\theta_{(k 1) X} \theta_{L Z} B T /|\Delta|<0 ; B<0
$$$$
\frac{\widehat{W}}{\hat{t}}=-\theta_{(k 1) X} \theta_{(k 2) Z} B S_{W} T /{ }_{|\Delta|}>0
$$

Where,

$$
\begin{aligned}
|\Delta|=\theta_{L Z} C- & \theta_{(k 2) Z} E+\theta_{S X} \theta_{L Y} \theta_{(k 2) Z} S_{W} A \\
& -\theta_{(k 1) X} \theta_{L Y} \theta_{(k 2) Z} S_{W} B \\
& >0 \text { and } S_{W}>0
\end{aligned}
$$

Another aspect of the result is informalization of the workforce and income inequality. Since the formal sector $\mathrm{Y}$ contracts and unskilled labour moves to the informal sector, thereby causing informalization of labour in the economy. Also, income inequality between skilled and unskilled labour of either type widens. Thus, the following proposition is immediate.

Proposition 1- Trade liberalization in form of a decline in tariff rate causes informalization of the workforce, widens income inequality, and growth of the informal sector, however skilled labour and capital owners in the informal sector gains.

\section{Labour Market Reform}

Labour market reforms are usually a part of globalization process which aims to increase returns on capital investment, profit accumulation smoother and making the formal sector of the economy to expand at a higher pace. Labour market reforms incorporate the change in hiring and firing regulations, demonstration rights by workers, social security benefits, wage regulation etc., however, our present study is specific to decline in union bargaining strength (i.e. $\hat{U}<0$ ) as one of the labour market reform policy. From differentiation of the factor prices w.r.t. $U$ we get the following results.

$$
\begin{gathered}
\widehat{W}_{S}=\frac{\left(\theta_{(k 1) X} \theta_{L Y} \theta_{L Z} C S_{U}-\theta_{(k 2) Z} E S_{U}\right) \widehat{U}}{|\Delta|}<0 \\
\hat{r}_{1}=\frac{\left(-\theta_{S X} \theta_{L Y} \theta_{L Z} C S_{U}+\theta_{S X} \theta_{L Y} \theta_{(k 2) Z} S_{U} E\right) \widehat{U}}{|\Delta|}>0 \\
\hat{r}_{2}=\frac{\left(-\theta_{S X} \theta_{L Z} \theta_{(k 1) Y} D S_{U}+\theta_{S X} \theta_{L Z} \theta_{L Y} A S_{U}-\theta_{(k 1) X} \theta_{L Z} \theta_{L Y} B S_{U}\right) \widehat{U}}{|\Delta|}<0 \\
\widehat{W}=\frac{\left(\theta_{S X} \theta_{(k 1) Y} \theta_{(k 2) Z} D S_{U}-\theta_{S X} \theta_{L Y} \theta_{(k 2) Z} A S_{U}+\theta_{(k 1) X} \theta_{L Y} \theta_{(k 2) Z} S_{U} B\right) \widehat{U}}{|\Delta|}>0 \\
\widehat{W}=\frac{\left(\theta_{S X} \theta_{(k 1) Y} \theta_{L Z} C S_{U}-\theta_{(k 2) Z} E S_{U}\right) \widehat{U}}{|\Delta|}<0
\end{gathered}
$$

Subtracting $\hat{\bar{W}}$ from $\hat{W}$, we get,

$$
\frac{\widehat{W}-\widehat{W}}{\widehat{U}}=\frac{\theta_{L Z} C S_{U}\left(\theta_{(k 1) X}-\theta_{(k 1) Y}\right)}{|\Delta|}>0 ; \theta_{(k 1) X}>\theta_{(k 1) Y}
$$

An intuitive explanation can be provided as follows. A decline in $U$ implies fall in unionized wage rate, $\bar{W}$ for given $\mathrm{W}$. Therefore, sector $\mathrm{Y}$ expands and demands more unskilled labour and type 1 capital, as a result $r_{1}$ and $W$ rises. Sector $X$ contracts and releases type 1 capital and sector $Z$ contracts and release unskilled labour. Since $X$ and $Z$ contract, their demand for skilled labour and capital of type 2 falls, as a consequence their return $\left(W_{S}\right.$ and $\left.r_{2}\right)$ also falls. The effect on income inequality can also be observed from eq. (2.9.1). Income inequality improves provided the sufficient condition that $\mathrm{X}$ is capital intensive relative to $\mathrm{Y}$ in distributive sense (Jones and Neary, 1984), i.e. $\theta_{(k 1) X}>\theta_{(k 1) Y}{ }^{10}$. The following proposition is immediate.

\footnotetext{
${ }^{10}$ Jones and Neary (1984) defined factor intensity for non HOSS structured model. The paper defined that factor intensity can be defined in distributive sense (i.e. relative share of expenditure on the particular factor) for the particular factor which is mobile across the sector.
} 
Proposition 2- Labour market reform in terms of decline in union strength of unskilled labour unambiguously raises informal wage rate and returns to formal sector capital owners, however formal sector workers loses. Income inequality (within formal sector) improves under the sufficient condition that $\theta_{(k 1) X}>\theta_{(k 1) Y}$ and income inequality (across formal and informal sector) unambiguously improves.

\section{Capital Account Liberalization}

Let us now consider an increase in foreign capital inflow $\left(K_{F 1}\right)$ due to the liberalization of capital account in the formal sector. Return on capital, falls due to increase in supply of capital. Since, capital is used in both the formal sectors ( $X$ and $Y$ ), both $X$ and $Y$ expand. As a result, demand for skilled labour in sector $X$ and demand for unskilled labour in sector $Y$ rises, and hence their return $W_{S}$ and $W$ rises respectively. A rise in $\mathrm{W}$ implies increase in formal sector wage $W$. Unskilled labour moves from the informal sector to the formal sector. The net effect on output is an expansion of the formal sector and contraction of the informal sector. Demand for type 2 capital fall in the informal sector and hence its return also falls. Within the formal sector income inequality worsens provided distributive share of capital is relatively larger in sector $\mathrm{X}$ compared to Y. Formal-informal sector unskilled wage inequality improves under the sufficient condition $\left(\theta_{(k 2) Z} S_{W}\right.$ $\left.-\theta_{L Z}\right)<0$. We thus get the following proposition.

Propostion 3- An increase in foreign capital inflow in the formal sector leads to unambiguous improvement in returns to all type of labour at the cost to capital owners, also the formal sector expands and the informal sector contracts.

\section{Sub case 2: Perfect Capital Mobility across Sectors}

In this section we assume that capital earns same return across all sectors, this implies capital is perfectly mobile across all sectors. All symbols have their usual meaning, however, return on capital now becomes and capital is denoted by $\mathrm{K}$.

The following sets of equations represent the economic structure.

$$
\begin{aligned}
& W_{S} a_{S X}+r a_{K X}=P_{X}^{*} \\
& \bar{W} a_{L Y}+r a_{K Y}=P_{Y}^{*}(1+t)=P_{Y} \\
& W a_{L Z}+r a_{K Z}=P_{Z}^{*} \\
& \bar{W}=\bar{W}(W, U) ; \frac{\partial \bar{W}}{\partial W}>0, \frac{\partial \bar{W}}{\partial U}>0
\end{aligned}
$$$$
a_{S X} X=S
$$$$
a_{L Y} Y+a_{L Z} Z=L
$$$$
a_{K X} X+a_{K Y} Y+a_{K Z} Z=K=K_{F}+K_{D}
$$

The model contains seven endogenous variables $W_{S^{\prime}} r, \bar{W}, W, X, Y$ and $Z$ and seven equations solves for them. Equation (3.2)-(3.4) solves for three factor prices $r, \bar{W}, W$. On substitution of $r$ in eq. (3.1), we get $W_{s}$. Therefore, factor prices are solved from the price system only. Hence, the model has decomposition property. From eq. (3.5), we get $X$ and on substitution of $X$ in eq. (3.7) together with eq. (3.6) solves for $Y$ and $Z$. Sector $Y$ and $Z$ in the model forms Hecksher-Ohlin Sub System (HOSS) which implies sector $Y$ and sector $Z$ can be classified in terms of factor intensity. This completes the determination of equilibrium in the model.

We also assume sector $Y$ to be capital intensive in value sense relative to sector $Z$. This is implied by the following condition.

$$
\frac{\theta_{L Z}}{\theta_{K Z}}>\frac{\theta_{L Y}}{\theta_{K Y}}=>\frac{W a_{L Z}}{a_{K Z}}>\frac{\bar{W} a_{L Y}^{11}}{a_{K Y}}
$$

\section{Comparative Statics-II}

We carry out the same comparative statics as in the preceding section.

4. Let us first consider the effect of trade liberalization. A fall in tariff rate ' $t$ ' implies a fall in the domestic price of sector $Y$. Fall in price of $Y$ leads to more than proportionate fall in interest rate and rise in the unskilled wage rate. Rise in $W$ implies an

\footnotetext{
${ }^{11}$ The condition is stronger condition than usual factor intensity condition, since $\bar{W}>W$. Hence, factor intensity in value sense also implies factor intensity in physical sense, i.e. aLZ/aKZ >aLY/aKY.
} 
increase in $\bar{W}$. $Y$ contracts and releases capital and labour. Capital moves to sector $X$ and it expands. Its demand for skilled labour rises thus rises. Sector $\mathrm{Z}$ also expands. The following result is thus obtained.

Proposition 4- A fall in tariff rate has a favourable effect on workers of either type, however, capital owner loses. Moreover, under perfect capital mobility a fall in tariff rate leads to informalization of formal unskilled labour.

\section{Capital Account Liberalization}

An increase in foreign capital leads Rybczynski effect which implies an expansion of sector $\mathrm{Y}$ and contraction of sector $Z$. The logic can be explained as follows. An increase in capital endowment due to inflow of foreign capital leads to expansion of sector $\mathrm{Y}$ since $\mathrm{Y}$ is capital intensive. $\mathrm{Y}$ expands therefore it draws unskilled labour from sector $Z$, this implies contraction of Z. Decomposition property of the model implies factor price remains unchanged. Thus we have the following proposition.

Proposition 5- An inflow of foreign capital leads to expansion of the formal sector and contraction of the informal sector.

\section{Labour Market Reform Policy}

A fall in union bargaining strength implies a fall in formal wage rate $\bar{W}$ for given informal wage W. Sector $Y$ thus expands and demands unskilled labour and capital. As result price of capital rises. Sector $X$ and sector $Z$ contract and releases capital for $Y$. Demand for skilled labour falls in $X$ thus skilled wage rate falls. Similarly, informal wage rate $\mathrm{W}$ falls. Movement of capital to sector $\mathrm{Y}$ leads to Rybczynski type effect and thus $\mathrm{Y}$ expands and $\mathrm{Z}$ contracts. Thus, the following proposition is immediate.

Proposition 6- Labour market reform in terms of fall in union strength leads to unambiguous loss to workers (both formal and informal labour) and improvement in capital owners' position. Also, the formal import competing sector expands and the informal agro based sector contracts.

\section{CONCLUSION}

The paper has attempted to offer a theoretical structure towards analyzing the influence of globalization, trade liberalization and labour market reform on factor income, sectoral growth, income inequality and informalization of labour. Under restricted capital mobility across the formal and informal sector, we obtained that tariff liberalization causes informalization of unskilled labour and widens income inequality. Labour market reform and foreign capital inflow leads to an increase in the formal employment. However, their effect on income inequality is ambiguous but can be improved under a particular sufficient condition that distributive share of capital is relatively larger in the skilled intensive sector compared to the low skilled formal sector. Results are slightly reversed when allowing for capital mobility across formal and informal sector. Under the regime of perfect capital mobility, tariff liberalization has favorable effect on either type of worker in terms of increased wage rate, however, it causes informalization of the workforce. Foreign capital inflow and decline in trade union strength unambiguously expands the scope for formalization of the labour force, however, a labour market reform policy dampens the income of the workers. Apart from analyzing the model to bring out the above propositions, the paper also digs out the serious trade-off that policy makers have to face to improve labour welfare. The trade-off is explained in terms of increased labour income and informalization of the workforce to improve labour welfare. The paper is limited to its analysis of a particular stylized model, however, there exist future scopes for extension of the model by incorporating non-traded informal intermediate sector and indexing the formal wage to food price. The paper also intends to look into possibilities of exploring such hidden tradeoffs that are inherent in the structure of the labour market.

\section{REFERENCES}

Beladi, Hamid, and Sugata Marjit. 1996. "An Analysis of RuralUrban Migration and Protection." The Canadian Journal of Economics, 29(4): 930-940.

Chaudhuri, Sarbajit, and Dibyendu Banerjee. 2006. “Economic Liberalization and Informal Wage in a Small Open Economy: Does Capital Mobility count?" Munich Personal RePEc Archive, MPRA, No. 1353.

Corden, W.M. and Findlay, R. 1975. Urban Unemployment, intersectoral capital mobility and development policy, Economica., 42: 59-78.

Jones, Ronald W. 1965. "The Structure of Simple General Equilibrium Models." The Journal of Political Economy, 73(6): 557-572. 
Jones, Ronald W. and Peter J. Neary. 1984. "Positive Theory of International Trade." In Handbook of Development Economics, Vol. 1, by Ronald W Jones and Peter Bain Kenen. North-Holland, Amsterdam.

Marjit, Sugata. 1981. "Agro-basedindustry and rural-urban migration- A case for an urban employment subsidy." Journal of Development Economics, pp. 393-398.

Marjit, Sugata and Dibyendu Maiti. 2005. Globalization, Reform and the Informal Sector. Research Paper No. 2005/12, Finland: UNU-WIDER.

Marjit, Sugata and Hamid Beladi. 2005. "Does Trade Increase Employment? A Developing Country Perspective." Indian Statistical Institute, ISID. Delhi.
Marjit, Sugata, Saibal Kar and Punyabrata Sarkar. 2004. "Capital Mobility and Informal Wage in a Small EconomyTwo Examples." South Asia Economic Journal, 5(2): 261-266.

Saikia, Dilip. 2017. "How Diversified is the Informal Manufacturing Sector Across Indian States?" Journal of Rural and Industrial Development, 5(2).

Shapiro, Carl and Joseph, E. Stiglitz. 1984. “Equilibrium Unemployment as a Worker Discipline Device." American Economic Review, 74: 433-44.

\section{APPENDIX}

Given all factor coefficients are function of their respective factor prices in that sector, we have:

$$
\left.\begin{array}{rl}
a_{s X} & =a_{s X}\left(w_{s}, r_{1}\right) \\
a_{k 1 X} & =a_{k 1 X}\left(w_{s}, r_{1}\right) \\
a_{l Y} & =a_{l Y}\left(\bar{w}, r_{1}\right) \\
a_{k 1 Y} & =a_{k 1 Y}\left(\bar{w}, r_{1}\right) \\
a_{l Z} & =a_{l Z}\left(w, r_{2}\right) \\
a_{k 2 Z} & =a_{k 2 Z}\left(w, r_{2}\right)
\end{array}\right\}
$$

Total differentiating (4) we get:

$$
\begin{aligned}
& \hat{a}_{s X}=S_{s s}^{X} \widehat{w}_{s}+S_{s k}^{X} \hat{r}_{1} \\
& \hat{a}_{k 1 X}=S_{k s}^{X} \widehat{w}_{s}+S_{k(k 1)}^{X} \hat{r}_{1} \\
& \hat{a}_{l Y}=S_{l l}^{Y} \widehat{\bar{w}}+S_{l k 1}^{Y} \hat{r}_{1} \\
& \hat{a}_{k 1 Y}=S_{k 1 l}^{Y} \widehat{\widehat{w}}+S_{(k 1)(k 1)}^{Y} \hat{r}_{1} \\
& \hat{a}_{l Z}=S_{l l}^{Z} \widehat{w}+S_{l k}^{Z} \hat{r}_{2} \\
& \hat{a}_{k 2 Z}=S_{k l}^{Z} \widehat{w}+S_{k k}^{Z} \hat{r}_{2}
\end{aligned}
$$

Where, $S_{j j}^{i}<0$ and $S_{j p}^{i}>0$ for $\mathrm{i}=\mathrm{X}, \mathrm{Y}, \mathrm{Z}$

and $\mathrm{j} \neq p$ for $\mathrm{j}, \mathrm{p}=\mathrm{L}, K_{1}, K_{2}, \mathrm{~S}$ 
Total differentiating equation (2.1) - (2.4), we get:

$$
\begin{aligned}
& \theta_{S X} \widehat{w}_{S}+\theta_{k 1 X} \hat{r}_{1}=0 \\
& \theta_{l Y} \widehat{\widehat{w}}+\theta_{k 1 Y} \hat{r}_{1}=\widehat{P}_{Y} \\
& \theta_{l Z} \widehat{w}+\theta_{k 2 Y} \hat{r}_{2}=0 \\
& \widehat{\bar{w}}-S_{w} \widehat{w}=S_{U} \widehat{U}
\end{aligned}
$$

Total differentiating (2.6.1):

$$
\begin{gathered}
\left(\frac{a_{l Y}}{a_{k 1 Y}}\right) \bar{k}_{1}-\left(\frac{a_{l Y} a_{k 1 X}}{a_{S X} a_{k 1 Y}}\right) \bar{S}+\left(\frac{a_{l Z}}{a_{k 2 Z}}\right) \bar{k}_{2}=\bar{L} \\
Y a_{l Y}\left(\hat{a}_{l Y}-\hat{a}_{k 1 Y}\right)+\frac{a_{l Y}}{a_{k 1 Y}}\left(\bar{k}_{1} \hat{\bar{k}}_{1}+\frac{\bar{S} a_{k 1 X}}{a_{S X}}\left(\hat{a}_{S X}-\hat{a}_{k 1 X}\right)\right) \\
+\frac{\bar{k}_{2} a_{l Z}}{a_{k 2 Z}}\left(\hat{\bar{k}}_{2}-\hat{a}_{k 2 Z}+\hat{a}_{l Z}\right)=0 \ldots
\end{gathered}
$$

Substituting (4.1) - (4.6) in equation (6) we get:

$$
\begin{aligned}
& \hat{r}_{1} A+\widehat{w}_{s} B+\hat{r}_{2} C+\widehat{\bar{w}} D+\widehat{w} E+F=0 \\
& A=\lambda_{l Y}\left(S_{l k}^{Y}-S_{k k}^{Y}\right)+\left(\frac{\lambda_{l Y}}{\lambda_{k 1 Y}}\right)\left(\frac{\lambda_{k 1 X}}{\lambda_{s X}}\right)\left(S_{s k}^{X}-S_{k k}^{X}\right)>0 \\
& B=\left(\frac{\lambda_{l Y}}{\lambda_{k 1 Y}}\right)\left(\frac{\lambda_{k 1 X}}{\lambda_{s X}}\right)\left(S_{s S}^{X}-S_{k S}^{X}\right)<0 \\
& C=\left(\frac{\lambda_{l Z}}{\lambda_{k 2 Z}}\right)\left(S_{l k}^{Z}-S_{k k}^{Z}\right)>0 \\
& D=\lambda_{l Y}\left(S_{l l}^{Y}-S_{k l}^{Y}\right)<0 \\
& E=\left(\frac{\lambda_{l Z}}{\lambda_{k 2 Z}}\right)\left(S_{l l}^{Z}-S_{k l}^{Z}\right)<0 \\
& F=\left(\frac{\lambda_{l Y}}{\lambda_{k 1 Y}}\right) \hat{\bar{k}}_{1}+\left(\frac{\lambda_{l Z}}{\lambda_{k 2 Z}}\right) \hat{\bar{k}}_{1}
\end{aligned}
$$

Representing equation (5.1) - (5.4) and (6') in matrix form:

$$
\begin{aligned}
& {\left[\begin{array}{ccccc}
\theta_{S X} & \theta_{k 1 X} & 0 & 0 & 0 \\
0 & \theta_{k 1 Y} & \theta_{l Y} & 0 & 0 \\
0 & 0 & 0 & \theta_{I Z} & \theta_{k 2 Z} \\
B & A & D & E & C \\
0 & 0 & 1 & -S_{w} & 0
\end{array}\right]\left[\begin{array}{c}
\widehat{w}_{S} \\
\hat{r}_{1} \\
\widehat{W} \\
\widehat{W} \\
\hat{r}_{2}
\end{array}\right]=\left[\begin{array}{c}
0 \\
\hat{P}_{Y} \\
0 \\
-F \\
S_{U} \widehat{U}
\end{array}\right]} \\
& \Delta=\left[\begin{array}{ccccc}
\theta_{S X} & \theta_{k 1 X} & 0 & 0 & 0 \\
0 & \theta_{k 1 Y} & \theta_{l Y} & 0 & 0 \\
0 & 0 & 0 & \theta_{l Z} & \theta_{k 2 Z} \\
B & A & D & E & C \\
0 & 0 & 1 & -S_{w} & 0
\end{array}\right] \\
& |\Delta|=\theta_{l Z} C-\theta_{k 2 Z} E+\theta_{s X} \theta_{l Y} \theta_{k 2 Z} S_{w} A-\theta_{k 1 X} \theta_{l Y} \theta_{k 2 Z} S_{w} B>0 \\
& T=\frac{t}{(1+t)}
\end{aligned}
$$


sp

Using Cramer's rule and Laplace theorem we solve for the unknowns and obtained the following results,

$$
\begin{aligned}
& \widehat{w}_{S}=\frac{-\theta_{k 1 X}\left\{\theta_{l Z} C-\theta_{k 2 Z}\left(D S_{w}+E\right)\right\} T \hat{t}+\theta_{k 1 X} \theta_{l Y}\left\{\theta_{l Z} C S_{U} \widehat{U}+\theta_{k 2 Z}\left(F S_{w}-E S_{U} \widehat{U}\right)\right\}}{\theta_{l Z} C-\theta_{k 2 Z} E+\theta_{s X} \theta_{l Y} \theta_{k 2 Z} S_{w} A-\theta_{k 1 X} \theta_{l Y} \theta_{k 2 Z} S_{w} B} \\
& \hat{r}_{1}=\frac{\left.\theta_{S X}\left\{-D S_{w} \theta_{k 2 Z}+\theta_{l Z} C-\theta_{k 2 Z} E\right)\right\} T \hat{t}-\theta_{s X} \theta_{l Y}\left\{\theta_{l Z} C S_{U} \widehat{U}+\theta_{k 2 Z}\left(F S_{w}-E S_{U} \widehat{U}\right)\right\}}{\theta_{l Z} C-\theta_{k 2 Z} E+\theta_{s X} \theta_{l Y} \theta_{k 2 Z} S_{w} A-\theta_{k 1 X} \theta_{l Y} \theta_{k 2 Z} S_{w} B} \\
& \widehat{\widehat{w}}=\frac{\theta_{s X} \theta_{k 1 Y}\left\{S_{U} \theta_{l Z} C \widehat{U}+\theta_{k 2 Z}\left(F S_{w}-E S_{U} \widehat{U}\right)\right\}+\theta_{s X} \theta_{k 2 Z} A S_{w} T \hat{t}-\theta_{k 1 X} \theta_{k 2 Z} B S_{w} \widehat{U} T \hat{t}}{\theta_{l Z} C-\theta_{k 2 Z} E+\theta_{s X} \theta_{l Y} \theta_{k 2 Z} S_{w} A-\theta_{k 1 X} \theta_{l Y} \theta_{k 2 Z} S_{w} B} \\
& \widehat{w}=\frac{\theta_{s X} \theta_{k 1 Y} \theta_{k 2 Z}\left\{D S_{U} \widehat{U}+F\right\}-\theta_{s X} \theta_{l Y} \theta_{k 2 Z} A S_{U} \widehat{U}+\theta_{s X} \theta_{k 2 Z} A T \hat{t}+\theta_{k 1 X} \theta_{l Y} \theta_{k 2 Z} B S_{U} \widehat{U}}{\theta_{l Z} C-\theta_{k 2 Z} E+\theta_{s X} \theta_{l Y} \theta_{k 2 Z} S_{w} A-\theta_{k 1 X} \theta_{l Y} \theta_{k 2 Z} S_{w} B} \\
& \hat{r}_{2} \\
& =\frac{\theta_{s X} \theta_{k 1 Y} \theta_{l Z}\left\{D S_{U} \widehat{U}+F\right\}-\theta_{s X} \theta_{l Y} \theta_{l Z} A S_{U} \widehat{U}-\theta_{s X} \theta_{l Z} A \hat{P}_{Y}-\theta_{k 1 X} \theta_{l Y} \theta_{l Z} B S_{U} \widehat{U}+\theta_{k 1 X} \theta_{l Z} B \widehat{P}_{Y}}{\theta_{l Z} C-\theta_{k 2 Z} E+\theta_{s X} \theta_{l Y} \theta_{k 2 Z} S_{w} A-\theta_{k 1 X} \theta_{l Y} \theta_{k 2 Z} S_{w} B}
\end{aligned}
$$

